\title{
[R]existindo aos poderes? Um breve ensaio sobre antropologia ontológica
}

\author{
Antônio Augusto Oliveira Gonçalves ${ }^{1}$
}

Universidade Federal de Goiás

Resumo: neste texto, recupero algumas ideias decorrentes do giro ontológico na antropologia, mormente, dialogo com autores como David Graeber, Eduardo Viveiros de Castro e Mauro Almeida. Ao longo do ensaio, além de tecer algumas continuidades e rupturas entre eles, procuro lançar luzes sobre uma questão: a aposta ontológica nas multiplicidades necessariamente despolitiza?

Palavras-chave: Incomensurabilidade; Ontologias; Políticas nativas; Diferença intensiva. 


\title{
[R]existing powers? A brief essay on ontological anthropology
}

\begin{abstract}
I recover some ideas arising from the ontological turn in anthropology, especially, dialogue with authors like David Graeber, Eduardo Viveiros de Castro and Mauro Almeida. Throughout the essay, in addition to weaving some continuities and ruptures between them, I try to shed light on one question: does the ontological bet on multiplicities necessarily depoliticize?
\end{abstract}

Keywords: Incomensurability; Ontologies; Native policies; Intensive difference.

\section{[R]existiendo a los poderes? Un breve ensayo sobre antropología ontológica}

\begin{abstract}
Resumen: en este texto, recupero algunas ideas derivadas del giro ontológico en la antropología, especialmente, dialogo con autores como David Graeber, Eduardo Viveiros de Castro y Mauro Almeida. A lo largo del ensayo, además de tejer algunas continuidades y rupturas entre ellos, procuro lanzar luces sobre una cuestión: la apuesta ontológica en las multiplicidades necesariamente despolitiza?
\end{abstract}

Palabras-clave: Incomensurabilidad; Ontologías; Políticas nativas; Diferencia intensiva. 


\begin{abstract}
o longo deste ensaio, almejo enfocar nos textos de ontologistas no âmbito A nacional, proponho assim rever algumas ideias de Mauro Almeida (2013), $\mathcal{L}$ e, além disso, não posso me furtar de perquirir os escritos daquele que é considerado um/a dos/as precursores/as do giro ontológico no Brasil, Viveiros de Castro (1996; 2006; 2008a; 2008b; 2015).

Entretanto, antes de embrenhar-me nas matas ameríndias ou suspeitar da presença de "Caipora" no Alto Juruá, farei uma breve visita a Madagascar, na qual pretendo refletir sobre a teoria do contrapoder imaginário de David Graeber (2011). Independente da proximidade e/ou distância de Graeber em relação aos/às ontologistas no Brasil, buscar esta saída pela tangente serve para responder uma pergunta estruturante desse ensaio teórico: será que a aposta ontológica nas multiplicidades necessariamente despolitiza? Os dados etnográficos e as categorias de cada um destes autores provavelmente devem deslocar a minha indagação para diferentes matizes políticos.
\end{abstract}

\title{
A violência espectral das sociedades sem Estado
}

David Graeber é um etnógrafo americano com posições políticas abertamente anarquistas, ex-orientando de Marshall Sahlins e professor de antropologia radicado no Reino Unido. Ao fundamentar a sua teoria do contrapoder imaginário, Graeber (2011) encontra inspiração no outro extremo do Canal da Mancha, em dois antropólogos franceses, Marcel Mauss (2003) e Pierre Clastres (2003).

De um lado, ele identifica na "economia da dádiva" de Mauss (2003) uma das primeiras reflexões antropológicas para pensar em moralidades alternativas nas sociedades sem Estado e sem mercado, em outro, Graeber recorre aos estudos de Clastres (2003). Em vida, este último contestava a tese evolucionista segundo a qual o Estado era uma forma apurada de organização política em comparação aos estágios anteriores. As comunidades amazônicas de Clastres eram gestadas em formas de autogoverno e em instituições da chefia, mobilizando certos mecanismos que impediam a emergência de domínio ou o monopólio do uso da força nas mãos de uns/as em detrimento dos/as demais, isto é, tratava-se sociedades erigidas contra o Estado. Tanto o circuito de dons e contradons, quanto os mecanismos políticos dos amazônicos pareciam iluminar um caminho possível para reler estas sociedades construídas num rechaço manifesto às lógicas do poder estatal e do mercado (GRAEBER, 2011).

No livro "Fragmentos de antropología anarquista", Graeber (2011) consegue ver nas sociedades anárquicas de Clastres (2003) e nas dádivas de Mauss (2003), formas de contrapoder revolucionário, uma vez que havia nelas um conjunto de instituições populares cuja finalidade era garantir que reis, dinastias, plutocratas e nobres jamais pudessem existir. A “máquina clastriana”, a suces- 
são de mecanismos existentes em sociedades que prezavam pelo consenso comunal, era renomeada pelo antropólogo americano enquanto um "aparato do contrapoder imaginário", no qual a semântica do prefixo "contra" residia precisamente naquele laivo inaudito, na latência, ou se preferem, num desdobramento dialético imanente em que as sociedades consensuais e igualitárias desenvolvem arranjos sociais para se precaverem da existência de relações de poder assimétricas e exacerbadas, expurgando do seu bojo resquícios da incidência dos mercados ou do poder do Estado (GRAEBER, 2011).

Logo, o pressuposto de partida em Graeber é a própria possibilidade concreta das sociedades igualitárias. Porém, se quase todas as sociedades se encontram imersas num emaranhado de contradições e estão, até certo limiar, digladiando consigo mesmas, como eram possíveis certos grupos étnicos manterem o consenso e serem igualitários em meio a esta disparidade de interesses?

A resposta para tal celeuma podia ser resolvida pelas evidências etnográficas: o autor buscou por casos de sociedades igualitárias na literatura antropológica e também se respaldou em suas incursões nas terras altas de Madagascar, entre 1989 e 1991. Após rever os escritos de Joanna Overing sobre os Piroa nos afluentes do Orinoco, inquirir o caso dos Tiv na Nigéria e, finalmente, se voltar para a sua experiência de campo entre os Malgaches, Graeber constatou que havia diversas maneiras de constituir e manter o consenso nestas sociedades. Por exemplo, os Tiv organizavam assembleias comunais na qual tentavam dirimir as contendas ou pequenas guerras entre os clãs; entre os Piroa se concedia demasiado valor à liberdade individual e eles/as se contrapunham ao controle por meio do acúmulo de riquezas ou no estabelecimento de hierarquias que inibiam a autonomia de cada qual; já os diversos grupos malgaches dispersos pela costa de Madagascar tendiam a serem avessos ao trabalho assalariado e suspeitavam de adultos/as que davam ordens aos/às demais; na verdade, estes/as eram considerados/as não-malgaches pelos/as nativos/as, pois eram assim que se portavam os colonos franceses, os donos de escravos e os reis loucos. Os Malgaches eram, em muitos sentidos, anarquistas e tomavam as decisões locais com base no consenso e em instituições informais (GRAEBER, 2011).

Apesar de tais sociedades buscarem garantir, por caminhos díspares, as vontades comunais sem recair no julgo de soberanos, colonizadores ou comerciantes locais, elas faziam um trabalho ideológico de identificação dos outros, ou seja, nas suas cosmologias haviam mundos aterradores, habitados por bruxos, magos e criaturas bicéfalas. Estes mundos eram uma espécie de resposta inversa ao pacifismo ou a autonomia imperante entre os entes humanos. Se, de um lado, os/as nativos/as contornavam as disputas através de acordos coletivos, em outro, os seus cosmos eram aterrorizados por espectros, figuras sobrenaturais em constante guerra entre si, isto é, o trabalho hercúleo para lograr o consenso trazia em seu cerne a emergência de espaços invisíveis, donde tanto se ocultava aquela violência intrínseca de que fala Graeber, quanto permitia calibrá-la, conter estes campos de batalha endógenos mediante a criação de zonas insurrecionais e flexuosas. É, sobretudo, através da relação com os entes não humanos que advêm os potenciais revolucionários e a criatividade social das sociedades igualitárias, conforme a teoria de Graeber (2011).

Consoante o autor, existiam continuidades ontológicas entre os mundos noturnos e suas implicações morais ou práticas para a vida dos/as nativos/as. Os Tiv, por exemplo, assumem que os homens só auferem poder e grandes fortunas se eles consomem as substâncias dos outros, o tsav. Pela cosmologia tiv, havia uma sociedade secreta de bruxos que destroçava pedaços de carne huma- 
na na comida daqueles que tinham os corações cobertos de tsav. Assim, grandes empreendedores ou os que mantinham certa fama e influência incorriam numa "dívida de carne" com os bruxos. De tempos em tempos, se realizava um movimento de caça aos/as culpados/as e vítimas de bruxaria com o intuito de destruir as estruturas emergentes de poder. A sociedade secreta personificava o governo invisível do país e somente através deste acerto de contas a cada nova geração, os Tiv podiam livrar-se do poder maligno dos bruxos. Os Piroa, por seu turno, também relatam a existência de mundos cujos deuses predadores travam batalhas com magos, de modo que as mortes na comunidade eram consequências de assassinatos espirituais (GRAEBER, 2011).

Logo, a violência espectral dos "magos" e "bruxas" tanto dava condições para equilibrar as divergências de interesses das sociedades sem Estado, quanto parecia conter uma reserva social de mudança revolucionária possível. Nesse ponto, o caso dos Malgaches é emblemático. Trata-se de uma sociedade em que qualquer um/a tem acesso aos espíritos e, por vezes, move ataques mágicos ou feitiços às pessoas demasiado ricas ou poderosas. As práticas de bruxaria podem ser maléficas, mas também expressam algo de propriamente malgache, afinal o mundo povoado por seres capazes de malefícios exprime a encarnação retorcida dos ideais de igualdade malgaches e ao mesmo tempo dá azo para reafirmação prática daquele ethos igualitário entre os entes humanos (GRAEBER, 2011).

Vejam que as formas de contrapoder imaginário se movem, para o autor, justamente pelas pressões inerentes ao projeto de uma sociedade em manter-se igualitária. Mas isto não quer dizer que a violência espectral das sociedades sem Estado sirva apenas para resolver as suas turbulências internas geradas por formas de desigualdade, o que corresponderia a uma interpretação errônea e funcionalista do pensamento de Graeber. Para o antropólogo americano, ao contrário, mesmo se fosse possível a completa inexistência de desigualdades, há sempre os problemas relativos à própria condição humana, dentre eles, as diferenças entre os sexos, a reprodução e a morte. É geralmente nesse campo das ontologias que tanto emergem certas vicissitudes, quanto se tenta mediá-las a partir da correlação entre o consenso comunal e as agências não humanas e espectrais:

[...] hasta cierto punto, todas esas turbulencias emergen de la propia naturaleza del ser humano. No existe ninguna sociedad que no considere la vida humana como, fundamentalmente, un problema, y por mucho que difieran en el tratamiento del mismo, consideran que la existencia del trabajo, el sexo y la reproducción está llena de dilemas, los deseos humanos son siempre volubles y además está el hecho de que todos vamos a morir. Así que hay mucho de lo que preocuparse. Ninguno de estos dilemas desaparecerá si eliminamos las desigualdades estructurales (aunque estoy seguro de que ello mejoraría radicalmente las cosas). [...] pero he sugerido, de las propias tensiones inherentes al projeto de proteger una sociedad igualitaria emerge una violencia espectral. (GRAEBER, 2011, p. 40)

A meu ver, depois de interpretar alguns textos dos/as ontologistas, havia algo que me soava um tanto hipostático nas formulações de Graeber. Resumir as complexidades do cosmos de cada um dos grupos indígenas em duas ou três páginas, descrevendo em termos gerais e, por vezes, imprecisos o que seria estes "mundos noturnos" me causou algum desalento interpretativo. O processo foi se acicatando com o decurso dos parágrafos e quando me deparei com arremate nos moldes de proposições basilares, tal como aparece no final do terceiro capítulo de Fragmentos, fui transportado quase inconscientemente às leituras 
dos/as ontologistas e ao documentário de Estamira ${ }^{2}$ dirigido por Marcos Prado (2004). De fato, o que me incomodava em Graeber era o ímpeto de conciliação entre ontologias distintas, com diferentes desdobramentos, mormente, em termos de gênero para as mulheres e homens daquelas etnias, e caracterizá-las enquanto resultado da "imaginação".

Cabe ressaltar que quando Graeber enxerga naqueles mundos noturnos a emergência de um contrapoder imaginário, ele tenta se distanciar e tecer críticas às formas canônicas do Ocidente, às maneiras afuniladas pelo pensamento político europeu (ou norte-americano) de pensar as identidades, o poder, o Estado, a exemplo dos gregos, contudo, pesa nas formulações do antropólogo americano certo pendor generalizante. Pergunto-me: quais as implicações de amarrar categorias e mundos que não foram devidamente explorados e reconhecê-los por um símile cognome? Não me deterei aqui em julgar os erros e acertos de Graeber, mas vejam que a aposta política do autor de encontrar, nos costumes e epistemologias nativas, táticas de se colocar fora do alcance do Estado, ou quem sabe, de literalmente ossificar Estados e nobres na forma de dentes, apetrechos e celebrações rituais, tal qual faziam os Sakalavas, parece distanciar Graeber (2011) dos predicados metodológicos dos/as ontologistas, a saber, o de levar a sério às concepções nativas e explicitar os limites do nosso arcabouço conceitual nessa tarefa.

A saída mais política e anárquica de Graeber produz não só uma miscelânea de deuses e magos imbricados num idêntico novelo de muitas pontas, mas também omite as defluências mais funestas dos mundos espectrais e noturnos para os/as seus/as nativos/as, expressa nas disparidades de gênero, em afecções corpóreas (VIVEIROS DE CASTRO, 1996), nos suicídios indígenas reincidentes. Mesmo se Estamira levante suas mãos e diga a Graeber "tudo que é imaginário, tem, existe, é", resta ainda tecer uma linha de fuga por entre a narrativa da interlocutora de Prado e os seres existentes na cosmologia malgache, por exemplo. Assim, parafraseando Viveiros de Castro (2015), sublinho que a partir das definições do que venha a ser o existente, o ponto de vista de Estamira sobre os Malgache não é o mesmo que o ponto de vista dos Malgache sobre Estamira. Entre os dois sentidos, o trajeto não é equivalente. Logo, para comparar três universos cosmológicos, Graeber teve de buscar um quarto ponto fora deles e talvez tenha sido justamente aí que as retas paralelas foram forçadas a se cruzar. Destarte, não apenas a geometria de Euclides fora negada, mas também as diferenças intensivas existentes entre os Tiv, Piroa e Malgaches.

\title{
$\mathrm{n}-\mathbf{1}=$ as multiplicidades mínimas de Viveiros de Castro
}

\begin{abstract}
Os dualismos são reais, não imaginários; não são mero efeito de um "viés ideológico", mas o resultado de um funcionamento ou estado específico da máquina abstrata. (VIVEIROS DE CASTRO, 2015, p. 126)
\end{abstract}

Se lá onde Viveiros de Castro subscreve a palavra "dualismos" substituíssemos pelos "mundos noturnos" ou a "violência espectral" de Graeber, teríamos um parâmetro da diferença do primeiro em relação ao segundo. Mas nesse caso, tomando por base os procedimentos do primeiro autor, as distâncias teóricas ou

${ }^{2}$ O documentário relata a história de Estamira Gomes de Sousa, mulher negra, na época com 63 anos de idade. Ela trabalhava na coleta de resíduos no aterro sanitário do Jardim Gramacho, no Rio de Janeiro. As cenas se intercalam entre os insights filosóficos da protagonista com passagens sobre a sua vida familiar. 
epistêmicas entre ele e o seu colega de profissão do outro lado do Atlântico não residiriam num regime da contradição, da negação plena, oposição simétrica ou num movimento dialético. Apegando-se às questões filosóficas de Deleuze (1995a; 1995b; 2010) ao longo dos parágrafos de Viveiros de Castro, diria que ensaiar disparidades e confluências teóricas entre ele e Graeber não é uma atividade contumaz na antropologia do primeiro. Viveiros de Castro parece ser mais assecla das saídas pela tangente, das linhas de fuga e das sínteses disjuntivas - a separação relacionante. É também assim que ele se desfaz dos dualismos. Viveiros de Castro é etnólogo, amerindianista, arguto leitor de Bruno Latour (2012), Marilyn Strathern (2006; 2014) e Roy Wagner (2010). O que lhe associa a esses/as autores/as também é o que o liga filosoficamente a Deleuze (1995a; 1995b; 2010). Estes quatro nomes da antropologia comungam num aspecto nevrálgico: o questionamento dos binarismos.

Viveiros de Castro leva a fundo dois procedimentos deleuzianos para libertar a antropologia da jaula epistêmica que ela se encontrava enclausurada, pelo menos, desde o século XVIII, quando as poderosas divisões do Ocidente começaram a se proliferar primeiro nos tratados de filosofia e depois foram sendo replicadas pelos manuais científicos, repercutindo antelações duais como: sujeito e objeto, natureza e cultura, indivíduo e sociedade. Para enfrentar tanto dualismos menores, quanto o divisor infernal entre um e múltiplo, primeiro, Viveiros de Castro os "desessencializa", retira deles o seu cariz frondoso, tratando-os de um modo "menor", mais enquanto veículos, modalizações e liames entre um ponto e outro, do que como objetos, emanações reificadas ou mesmo máximas de pensamento. Por isso que as multiplicidades se desatrelam da fórmula $n+1$ cujo produto reacende as transcendências abstratas e unidades totalizantes para ceder lugar assim à equação n-1. O múltiplo ontológico e outros mundos possíveis do autor surgem como que por subtração, algo menor que um, em que o resultado não é equivalente a justapor tartarugas sobre tartarugas, como prefere a semiótica de Geertz (1978), senão em cercar o binômio de minorações (VIVEIROS DE CASTRO, 2015).

Assim, os resultados passíveis de serem computados pela equação n-1 não são em nada óbvios, não se desobstrui o horizonte limiar dos prisioneiros da Caverna, substituindo + por - e provendo a gruta metafísica de desconstruções. O crucial é facultar a travessia dos detentos de Platão e, para tanto, ao invés de proceder com negações e silogismos reversos cujo intento seria objetar negativamente os dualismos, Viveiros de Castro recomenda se desvencilhar das oposições binárias circunspectamente, sem cair em arapucas circulares, abrindo linhas de fuga por entre os dois termos. Logo, o segundo procedimento do autor se traduz na constituição de multiplicidades mínimas que vão se transformando e sendo reciprocamente afetadas à medida que se operam decalques, do polo extensivo em relação ao virtual intensivo, e inclusões disjuntivas, do polo virtual intensivo em direção ao extensivo. Isto é, para Viveiros de Castro, relatar a perspectiva da dádiva sobre a mercadoria não é o equipolente da perspectiva da mercadoria sobre a dádiva. Há, entre elas, uma imbricação mútua assimétrica (VIVEIROS DE CASTRO, 2015).

Porém, até então, nada falei sobre os polos de Deleuze (1995a; 1995b) e minha leitora (ou leitor) poderia objetar-me que minhas prolepses no curso dos argumentos mais confundem que explicam. Pois bem, cá estou para esclarecer quais as implicações mútuas se produzem entre os binômios como extensivointensivo e mercadoria-dádiva. Conforme pontua Viveiros de Castro, o repertório de conceitos em Deleuze é densamente permeado pelas díades: liso e estria- 
do, linha e segmento, diferença e repetição, fluxos e quanta, atual e virtual, extensivo e intensivo. Contudo, as dualidades deleuzianas se transmutam conforme nos fixamos no ponto de vista de um polo ou de outro, quer dizer, na medida em que os polos vão relacionalmente se implicando entre si, isto produz alterações num polo e no outro, o que se refaz recorrentemente. Cabe sublinhar que as transformações entre as díades jamais são simétricas, pois o percurso do domínio 1 em relação ao domínio 2 e deste em relação àquele não é correspondente (VIVEIROS DE CASTRO, 2015). Algo bem próximo ao que alega Holbraad (2014, p. 134): "el giro ontológico hace virar es justamente el procedimiento negativo de la deconstrucción hacia un procedimiento positivo de reconstrucción del conocimiento 2 ".

Com tal frase, Holbraad (2014) didaticamente assinala algumas distâncias entre a antropologia pós-moderna, adepta à desconstrução dos métodos positivistas e hermenêuticos, e os/as seguidores/as do giro ontológico, críticos/as das dualidades e cisões do Ocidente. Ainda na frase do autor, retomando as modalizações de Deleuze sobre os decalques e as sínteses disjuntivas, na desconstrução de A sobre B e na reconstrução de B sobre A, os dois termos, A e B, em meio a estes procedimentos, já não são mais os mesmos, movendo alhures na síntese separativa - ou disjunção relacionante - que os imbrica de modo recíproco e desigual. Trocando em miúdos, entre os dois polos, se a perspectiva do polo intensivo (liso, molecular, rizomático, flexível e virtual) em relação ao outro, há um regime de linha de fuga, na qual as implicações e sínteses disjuntivas retratam as diferenças intensivas - ou devires - do polo extensivo no polo virtual; do ponto de vista do polo extensivo (estriado, molar, arborescente, duro e atual), existe uma relação de oposição - ou regime de contradição - com o primeiro, em que o primeiro polo coexiste no segundo enquanto síntese limitativa, ou melhor, uma separação excludente em relação a ele (VIVEIROS DE CASTRO, 2015).

A complementaridade extremamente assimétrica sobre qual se assentam as dualidades de Deleuze (1995a; 1995b) se exprime até nos processos relacionais de um polo a outro: enquanto os mapas rizomáticos do polo virtual são frequentemente totalizados e consolidados pelos decalques do polo extensivoatual, o processo rizomático do extremo intensivo induz deformações - ou torções metodológicas - nos decalques arborescentes do polo atual-extensivo. Quando Viveiros de Castro (2015) predica a relevância de aprofundar nas concepções nativas para fraturar os nossos pressupostos ontológicos, ele está creditando as suas fichas nas potenciais torções do polo intensivo - nativo, ameríndio, ou quem sabe, melanésio - em relação ao polo extensivo - dicotômico e Ocidental - e fazendo a translação de toda a distinção-implicação das polaridades deleuzianas para o campo da antropologia. E talvez, não seja exagero dizer que provavelmente foi através de Deleuze que Viveiros de Castro prodigalizou nas ontologias: "é como se cada polo apreendesse sua relação com o outro segundo sua própria natureza" (VIVEIROS DE CASTRO, 2015, p. 128).

De novo aqui, aparece Viveiros de Castro enquanto partidário das posições de Strathern e Wagner. Os modos da invenção e da convenção na estilística de Wagner (2010) transparecem também nas construções vacilantes de Strathern (2006; 2014), quando a autora mobiliza polaridades das trocas melanésias articuladas a certos marcadores de gênero, um polo jamais é inócuo em relação ao outro, fosse ele masculino ou feminino, fossem nas formas de manipulação das riquezas hagen, cada polaridade era descrita etnograficamente como uma variante ou transformação da outra. Partindo dos influxos deleuzianos, espero que 
nessa altura do texto tenha se tornado inteligível porque o trajeto nos dois sentidos não é igual. Em meio a decalques arborescentes e deformações anárquicas, a síntese disjuntiva expõe o processo de interpressuposição assimétrica sob o qual as descrições etnográficas de Wagner, Strathern e Viveiros de Castro oscilam e se entrecruzam - em termos das polaridades internas de suas obras -, da mesma maneira que lança luzes sobre as distâncias internas e externas que atravessam o percurso da dádiva em relação à mercadoria, e desta em relação àquela (VIVEIROS DE CASTRO, 2015).

O esmero de ultrapassar as fruições hilemórficas da modernidade mediante aos "dualismos provisórios" de Deleuze (VIVEIROS DE CASTRO, 2008a) faz com que conforme as coisas estão disjuntamente imbricadas, tornam-se assim pontos iniciáticos para chegar alhures, nós sejamos cada vez mais propelidos/as a demandar a ação de intermediários/as, sujeitos que negociem com as multiplicidades heterogêneas. É assim que Viveiros de Castro descreve a mediação cósmica entre os espíritos xapiripë e os Brancos pelo líder yanomami, Davi Kopenawa:

\begin{abstract}
Se o xamanismo é essencialmente uma diplomacia cósmica dedicada à tradução entre pontos de vista ontologicamente heterogêneos, então o discurso de Kopenawa não é apenas uma narrativa sobre certos conteúdos xamânicos - a saber, os espíritos que os xamãs fazem falar e agir; ele é uma forma xamânica em si mesma, um exemplo de xamanismo em ação, no qual um xamã tanto fala sobre os espíritos para os Brancos, como sobre os Brancos a partir dos espíritos, e ambas estas coisas através de um intermediário, ele mesmo um Branco que fala yanomani. (VIVEIROS DE CASTRO, 2006, p. 320)
\end{abstract}

Se, por vezes, vemos evidentes incidências de Deleuze (1995a; 1995b) nos argumentos de Viveiros de Castro em meneios intensivamente extensivos e o contrário - extensivamente intensivos -, por outro, esta filiação filosófica acaba por se alastrar para os mais diversos nichos de pensamento, nos vislumbres viveirianos sobre o Estado, significado enquanto um "aparelho de captura semiótico-material”, isto é, o autor relê a concepção clastreana da "Sociedade contra o Estado" (CLASTRES, 2003), considerando o Estado não como uma prefiguração existente em instituições políticas, mas sim na qualidade de uma transcendência absoluta com habilidades de captura e contra-definição ontológica. O caso típico entre os amazônicos é o confronto indígena com espíritos na mata. Os encontros fatídicos com alteridades-espírito, sobretudo, quando se está solitário/a e/ou com os laços sociais distendidos, sem a presença de parentes para se resguardar do olhar certeiro e interpelador da onça, são, para Viveiros de Castro, a própria materialização repentina do Estado entre os amazônicos. Ao se deparar com uma sucuri e ser apanhado pelo contato ocular dela, o indígena reconhece nela um agente humano e nisso ele se vê capturado numa crise psico-ontológica em que a sua própria definição de humanidade é posta em jogo (VIVEIROS DE CASTRO, 2008b). Quer dizer, o Estado assume a natureza de um encontro, ou melhor, o evento do encontro com agentes sobrenaturais, segundo o antropólogo (VIVEIROS DE CASTRO, 2008b, p. 242):

\footnotetext{
O mundo indígena é um mundo ao mesmo tempo politeísta, perspectivista e contra o Estado. Essas três coisas vão juntas. A inexistência de um deus único, transcendente, absoluto, vai junto com a dificuldade que têm as tradições intelectuais indígenas de pensar em "modo-Estado" - dificuldade que é apenas o modo pelo qual aparece a nossos olhos a força dos mecanismos de conjuração-antecipação do Estado nessas sociedades, ou de serem pensadas pelo Estado - dificuldade que se exprime na impossibilidade de outra relação do Estado com essas sociedades que não seja a captura e a sobrecodificação.
} 
A primeira pergunta que me faço é: será? Tanto a definição do Estado como aparato de captura sobrenatural, quanto os argumentos correlatos de Viveiros de Castro que enxergam entre o Estado e os amazônicos um profundo vazio relacional, me parecem simplificações excessivas. Pergunto-me: e a FUNAI? ${ }^{3}$ E os confrontos indígenas pela delimitação das fronteiras de reserva? Quais as consequências, por exemplo, da construção da hidrelétrica de Tucuruí para os Parakanã (VIDAL, 1983)? Todos estes episódios correm num vazio político? Não posso deixar de evocar as críticas de Lucas Bessire e David Bond (2014) em relação ao giro ontológico. Para eles, os/as ontologistas com intuito de valorar a incomensurabilidade radical que separam indígenas e modernos, apagaram as constrições políticas e outras tantas violências impingidas contra os/as indígenas sob a salvaguarda ou mesmo com a intervenção direta do Estado. Além de não desenvolverem análises rentes às atualidades indígenas, os/a partidários/as das multiplicidades ignoram, por exemplo, como fazendas, complexos industriais, plantações, companhias de biotecnologia e as ações do Estado ante aos desastres, procuraram, cada qual a seu modo, por meios inovadores e coercitivos, preservar as vidas que importam (BESSIRE; BOND, 2014).

Conforme Bessire e Bond (2014), as inflexões ontológicas se pautam numa crítica acadêmica das categorias modernas, mais do que se dirigirem às implicações sociais de tais conhecimentos. É como se elas se voltassem para os templos da modernidade tentando romper com as fundações, mas, em troca, construíssem sólidas barreiras no entorno da sua cidadela científica, uma espécie de Torre de Marfim invisível a si mesma, edifício paradoxalmente sustentado pelas hierarquias que tenta pugnar. Ademais, se a saída das prisões epistêmicas dissuadidas pelos binarismos fez os/as ontologistas recorrerem às incomensurabilidades, as imanências e diferenças intensivas de Deleuze (1995a; 1995b), por outro, tais predileções teóricas recaem numa dupla implicância: primeiro, a incomensurabilidade empregue para driblar os dualismos, produz um binarismo de longa monta, cavando uma profunda fossa existencial entre modernos e nãomodernos; assim mais uma vez os/as ontologistas despencam pelos buracos que assinalam; em segundo lugar, a semântica das imanências reside na natureza do prognóstico, nas alternativas outras que as ontologias podem revelar sobre o futuro, entretanto, ao seguir por estas linhas, os/as autores/as do giro correm o risco de projetar a incomensurabilidade nos entes, antes de tentar compreendêlos na sua contingência mesma (BESSIRE; BOND, 2014). Dar um passo atrás, antes de perfilar aparições indiscerníveis de seres, possibilita entrever a pujança de interesses contraditórios ou processos violentos que avalizam a existência do existente, por assim dizer.

Isto posto, depois de retomar algumas críticas passíveis de serem direcionadas ao pensamento de Viveiros de Castro, pretendo agora, ao estilo de uma tréplica, conceder às vezes a outro sequaz das ontologias, Mauro Almeida (2013). Em seu texto, há um percurso metodológico que veicula os debates em torno das multiplicidades com o campo do poder, de maneira politizada e diligente. Para o autor, a existência dos seres não é somente um projeto de conhecimento, senão um processo atravessado por lutas pragmáticas e guerras ontológicas. 


\title{
Ontologias e encontros pragmáticos
}

Mauro Almeida, professor da Unicamp, etnólogo, participou da fundação da reserva extrativista do Alto Juruá, no Estado do Acre. No texto "Caipora e outros conflitos ontológicos”, Almeida (2013) analisa as dissonâncias e compatibilidades entre quatro modelos aptos a interpretar as atividades de caça na reserva, a saber: o modelo da extração sustentável, "ontologia-Caipora", modelo "fonte-sumidouro", ontologia econômica mercantil. O autor articula as definições das ontologias com a pragmática, isto é, aquilo que, para Viveiros de Castro (2008b), se expressa nos súbitos encontros indígenas com o sobrenatural na floresta, donde vísceras, afecções e capturas de alma se entrecruzam com o plano das imanências, desponta para Almeida (2013) sob outro prisma analítico. Inspirado pela fenomenologia de Husserl e o pós-positivismo de Quine, Almeida descentra as multiplicidades em dois âmbitos:

\begin{abstract}
[...] ontologias são o acervo de pressupostos sobre o que existe. Encontros com o que existe pertencem ao âmbito pragmático. Ontologias e encontros pragmáticos não são, contudo, separáveis. Pode-se ver isso já a partir da seguinte consideração: pressupostos ontológicos dão sentido, ou permitem interpretar, encontros pragmáticos, mas vão além de qualquer encontro particular, seja qual for seu número [...] "tudo se passa como se" o mundo existisse de fato conforme a ontologia em questão, mas há sempre um resíduo maior ou menor que pode levar a transformação dos pressupostos ontológicos. (ALMEIDA, 2013, p. 9)
\end{abstract}

O valor de distinguir coisas que, todavia, não são apartáveis, revertem os esquemas analíticos desprendidos das ontologias em algo menos estático e mais processual. Se os encontros com entidades e os episódios ulteriores a eles agem sobre o domínio dos pressupostos do que existe, então o que existe não se dá de uma vez por todas, como se um corpo anacrônico fosse imbuído no domínio duma existência sem jamais evadir das suas carapaças ontológicas. Assim, a distinção conceitual de Almeida tem, ao menos, duas vantagens: abala as fronteiras entre o existente e o não existente, tornando-as instáveis, passíveis de serem revistas pelos encontros pragmáticos; segundo, os liames entre uma ontologia e outra não são tão incomensuráveis assim a ponto delas serem invisíveis uma em relação a outra, afinal existe a possibilidade de duas formulações se cruzarem, estabelecendo discordâncias em termos dos pressupostos e, por vezes, chegando a travar conflitos ontológicos pelas quais a existência de uma entidade - por ex. "Caipora" - pode ser posta em jogo pelo arsenal de existentes da segunda ontologia. Vê-se então como as críticas de Bessire e Bond (2014) a Viveiros de Castro são, em certo sentido, revistas pelos argumentos de Almeida, pois as multiplicidades revertem-se mais do que uma crítica epistêmica dos modos de conhecer, lançando raízes num campo de lutas por meio do qual o reconhecimento dos seres está aberto a embates existenciais (ALMEIDA, 2013).

Os quatro modelos interpretativos das práticas de caça no Alto Juruá explicitam como um acervo de pressupostos pode colocar em risco a existência de outro, no sentido pragmático do processo. Vamos por partes, distinguirei os modelos antes de adentrar nos seus pontos de intersecção. O primeiro é o cânone interpretativo dos manuais de economia ecológica e se caracteriza por estipular uma taxa de extração sustentável, é como se a população-biomassa além de se reproduzir deixasse uma alíquota residual, a "taxa ótima de extração", a ser explorada de modo a maximizar os seus ganhos efetivos. O segundo modelo é a ontologia-Caipora. Entre os amazônicos, Caipora designa um ente que cria os animais da mata e intermedeia o acesso dos caçadores a suas presas. Para tanto, ela precisa do território para propiciar a reprodução dos bichos e cuidar dos se- 
res feridos em alguns lugares da mata. Caso os caçadores não respeitem os refúgios de caça e os dias de Caipora - ex. evita-se caçar durante certos dias da semana e o consumo de algumas espécies em respeito ao ente - , isto prejudica o acesso deles à caça (ALMEIDA, 2013).

Ainda no que se refere ao segundo modelo, se Caipora irrompe como um ser cuja existência se dissipa pelos contornos do território, "panema" é o mediador entre Caipora e uma teia de nexos que se prolonga tão logo a carcaça do animal abatido se despedace e seja distribuída entre os/as vizinhos/as. Em sentido lato, panema translada a circunspecção no entorno de Caipora em regras de etiqueta no trato do corpo do animal expressas desde o transporte da caça até o consumo recíproco da carne. Pode-se incorrer no tema moral do insulto, corolário quase imediato de panema, por diversas maneiras: caso o caçador passe a perna ou urine sobre a presa; quando cadelas no cio se aproximam de seus ossos e vísceras; há também o risco do consumo da carne entre mulheres menstruadas ou grávidas, o que constitui um grave insulto ao cadáver. Trocando em miúdos, panema envolve a complexa rede de entes, sejam eles, caçadores, espingardas, cães ou vizinhos/as, numa trama de relações que os conecta à Caipora. Uma vez insultado o corpo da presa, a presença de Caipora aturde os caçadores em suas novas incursões à mata. Ela o faz que se percam pela floresta, voltem com sinais de acoite na pele, com as vestes rasgadas, enfim, os "eventos-panema" funcionam como réstias das aparições subsequentes de Caipora (ALMEIDA, 2013).

Em meados de 1990, o modelo fonte-sumidouro começou a entrar em voga e disputar espaço com os/as adeptos/as do modelo de extração sustentável. Enquanto o último preza em calcular o número de transeptos na floresta - montante de animais abatidos -, o primeiro mensurava a porção do território que estava fora do alcance dos caçadores. Mesmo o modelo "torneira-e-ralo" - ou fonte-sumidouro - sendo avesso à ontologia-Caipora, na prática ele possibilitava cumprir com uma das regras para evitar panema, ou seja, ao resguardar uma parcela do território, o modelo correspondia ao preceito de respeito aos refúgios de caça, os lugares por onde Caipora dava provisões aos seres feridos na mata (ALMEIDA, 2013).

Por fim, o quarto e último modelo é a ontologia mercantil econômica. A própria existência deste modelo é condicionada ao advento da caçada comercial, ato de subordinação da vida silvestre às flutuações e demandas do mercado. Incorporado a tal ontologia, as pacas, antas e macacos, por exemplo, seriam processadas e transformadas em subprodutos para o consumo do mercado, tornando-se assim entes conversíveis em dinheiro. Neste caso, a textura que interconecta humanos, não humanos e objetos é o dinheiro-valor. Enquanto que na ontologia-Caipora, é a "textura-panema” responsável por interligar os sujeitos, entes, instrumentos e animais-presas numa rede de circulação e reciprocidade. Então, o despontar da textura-dinheiro implica uma síntese limitativa, em consonância com os lampejos de Deleuze (1995a; 1995b), o polo extensivo só pode se afirmar contradizendo a existência do polo virtual, quer dizer, imbuídos na ontologia-mercantil, a negociação entre predadores e animais é subsumida por uma textura englobante e auto-excludente em relação à "ontologia-panema". Em suma, no encontro entre Caipora e o mercado, "não há diferença ontológica, mas destruição de uma ontologia por outra” (ALMEIDA, 2013, p. 22).

Se no convívio pragmático com o modelo fonte-sumidouro, Caipora sobrevive ainda que sob critério de verdade parcial para ambas as ontologias, com o manejo e venda de carcaças para o mercado, a situação se altera profundamente, uma vez que a limitação excludente é tônica da textura-dinheiro. A ontologia- 
mercantil só pode se suster como legítima promovendo o extermínio de Caipora. Reafirmo o que está em questão não é simplesmente um embate de ideias, em meio a idas e vindas no esteio de práticas maiêuticas, é mais do que isto. "Não se trata de conflitos culturais, e sim de guerras ontológicas, porque o que está em jogo é a existência de entes no sentido pragmático, questão de vida ou morte para Caipora, para antas e macacos" (ALMEIDA, 2013, p. 22).

Nos instantes finais de seu texto, Almeida cinde e conjuga dois domínios de atuação possíveis aos/as ontologistas, apontando assim para um eventual desiderato das multiplicidades:

\begin{abstract}
É resultado de lutas pelo reconhecimento em que estão em jogo redes de pessoasanimais-Caipora, redes de mulheres-mandiocas-saberes coletivos e redes Estadoantropólogos-quilombolas. Há uma conexão entre domínio da economia ontológica (produção) e ontologia política (conhecimento). Essas expressões não são mais sinônimas, mas contêm uma nuança: a primeira trata de conflitos de produção e distribuição de entes, e a segunda trata do confronto político entre mundos possíveis além do mundo das mercadorias e do Estado Nacional. (ALMEIDA, 2013, p. 25)
\end{abstract}

\title{
Considerações finais
}

Este último excerto retoma a pergunta que fiz na introdução deste ensaio: a aposta nas multiplicidades despolitiza? Não necessariamente. Em certa medida, as respostas para tal indagação dependem das "políticas etnográficas" (ROBERTI-JUNIOR; CARIAGA; SEGATA, 2015; RIFIOTIS, 2016) que lançamos mão, as maneiras como articulamos campos teóricos, metodológicos e políticos ao registrar e fazer ouvir as narrativas de nossos/as interlocutores/as. Entretanto, no âmbito da antropologia ontológica, as respostas para minha pergunta se tornam demasiado tênues, aqui e ali as linhas de fuga parecem se esquivar do seu campo de forças para se voltarem sobre si mesmas, nos meandros de suas imanências e devires. Cabe, contudo, insistir na questão: estamos aplainando desigualdades na busca pelo incomensurável ou [r]existindo aos poderes?

Recebido em 24 de fevereiro de 2018.

Aprovado em 28 de maio de 2018.

\section{Referências}

ALMEIDA, M. W. B. de. Caipora e outros conflitos ontológicos. Revista de Antropologia da UFSCar. São Carlos, UFSCAR, v. 5, n. 1, p.7-28, 2013.

BESSIRE, L.; BOND, D. Ontological anthropology and the deferral of critique. American Ethnologist. Malden, American Anthropological Association, v. 41, n. 3, p. 440-456, 2014.

CLASTRES, P. A sociedade contra o Estado: pesquisas de antropologia política. São Paulo, Cosac Naify, 2003.

DELEUZE, G.; GUATTARI, F. $O$ anti-Édipo. Capitalismo e esquizofrenia 1. São Paulo, Editora 34, 2010. 
DELEUZE, G.; GUATTARI, F. Mil platôs. Capitalismo e esquizofrenia 2, v. 1. São Paulo, Editora 34, 1995a.

DELEUZE, G.; GUATTARI, F. Mil platôs. Capitalismo e esquizofrenia 2, v. 2. São Paulo, Editora 34, 1995b.

GEERTZ, C. A interpretação das culturas. Rio de Janeiro, Jorge Zahar Ed., 1978.

GRAEBER, D. Fragmentos de uma antropología anarquista. Barcelona, Virus Editorial, 2011.

HOLBRAAD, M. Tres provocaciones ontológicas. Ankulegi. Donostian, Ankulegi Asociación Vasca de Antropología, n. 18, p. 127-139, 2014.

LATOUR, B. Reagregando o social: uma introdução à teoria do ator-rede. Salvador/Bauru, Udufba/Edusc, 2012.

MAUSS, M. Sociologia e Antropologia. São Paulo, Cosac Naify, 2003.

PRADO, M. Estamira. Rio de Janeiro, RioFilmeZazen, 2004. Documentário.

RIFIOTIS, T. Etnografia no Ciberespaço como "Repovoamento" e Explicação. In: SEGATA, J.; RIOFIOTIS, T. Políticas etnográficas no campo da Cibercultura. Brasília, ABA Publicações; Joinville, Ed. Letradágua, 2016, p. 129-152.

ROBERTI-JÚNIOR, J. P.; CARIAGA, D. E.; SEGATA, J. Antropologia como (In)Disciplina: notas sobre uma relação imprecisa entre campo e escrita. Ilha Revista de Antropologia. Florianópolis, UFSC, v. 17, n. 2, p. 101-122, 2015.

STRATHERN, M. O gênero da dádiva: problemas com as mulheres e problemas com a sociedade na Melanésia. Campinas, Editora da Unicamp, 2006.

STRATHERN, M. O efeito etnográfico e outros ensaios. São Paulo, Cosac Naify, 2014 .

VIDAL, L. O espaço habitado entre os Kaiapo-Xikrin (Jê) e os Parakanã (Tupi) do Médio Tocantins, Pará. In: NOVAES, S. C. (Orgs.) Habitações Indígenas. São Paulo, Edusp, 1983, p. 77-102.

VIVEIROS DE CASTRO, E. Os pronomes cosmológicos e o perspectivismo ameríndio. Mana. Rio de Janeiro, UFRJ, v. 2, n. 2, p. 115-144, 1996.

VIVEIROS DE CASTRO, E. A floresta de cristal: notas sobre a ontologia dos espíritos amazônicos. Cadernos de Campo. São Paulo, USP, n. 14/15, p. 319-338, 2006.

VIVEIROS DE CASTRO, E.; GOLDMAN, M. O que pretendemos é desenvolver conexões transversais. In: SZTUTMAN, Renato. (Org.). Eduardo Viveiros de Castro. Encontros. Rio de Janeiro, Azougue, 2008a, p. 200-225.

VIVEIROS DE CASTRO, E. Uma boa política é aquela que multiplica os possíveis. In: SZTUTMAN, Renato. (Org.). Eduardo Viveiros de Castro. Encontros. Rio de Janeiro, Azougue, 2008b, p. 226-259.

VIVEIROS DE CASTRO, E. "Uma antissociologia das multiplicidades". In: VIVEIROS DE CASTRO, E. Metafísicas canibais: elementos para uma antropologia pós-estrutural. São Paulo, Cosac Naify, 2015, p. 113-132. 